\title{
Primary Bone Xanthoma: A Case Report
}

\author{
Parul Singh, Raji Naidu*, Uma Chaturvedi and Susan Cherian \\ BARC Hospital, Mumbai
}

\begin{abstract}
Xanthoma of bone is a rare disorder of bone which occurs due to cholesterol deposits in the bone. Clinically the patients usually present with pain or fracture of the affected bone. Radiologically it presents as a lytic lesion, often with cortical expansion or disruption. Xanthoma of bone is usually associated with hyperlipidemia but rare cases of non- hyperlipidemia xanthoma are also reported, termed as primary bone xanthoma. Here we present a rare case of a 46-year-old male who presented with pain and swelling in the right middle finger. $\mathrm{X}$ ray showed lytic lesion in the proximal phalanx of right middle finger. Laboratory tests showed normal lipid profile. Bone biopsy and histological examination is necessary for diagnosis and to differentiate it from Rosai-Dorfman disease, Langerhans cell histiocytosis and fibrous/post traumatic dysplasia, malignant fibrous histiocytoma, or metastatic renal cell carcinoma. A diagnosis of primary bone xanthoma was made based on histology and immunohistochemistry. The fracture was treated surgically. The case report emphasises the role of histology in diagnosis of this rare clinical entity.
\end{abstract}

Keywords: Hyperlipidemia, Xanthoma, Bone, Primary

\section{Introduction}

Xanthoma is a rare bone disorder which is mostly associated with endocrine or metabolic diseases having increased cholesterol levels, hypolipoproteinemia Type II \& III, hypothyroidism, diabetes mellitus and lipoprotein lipase deficiency, hence called secondary bone xanthoma. ${ }^{[1-4]} \mathrm{A}$ few cases have been reported in non-hyperlipidemic states termed as primary bone xanthoma. ${ }^{[3-5]}$ Various bone lesions can present with xanthomatous appearance histologically, e.g., fibrous dysplasia, giant cell tumor, simple bone cyst, fibroma, chondroblastoma, fibrous histiocytoma, histiocytosis $\mathrm{X}$ and chronic osteomyelitis, $[1-2,6]$ which makes it necessary to rule out these disorders before giving a diagnosis of bone xanthoma.

\section{Case Report}

A 46-year-old male presented to the orthopaedics outpatient department with complaints of swelling in the right middle finger along with pain and reduced movement of the finger. He had a history of mild trauma to the right middle finger while playing. He had no history of hypertension, diabetes or any lipid disorder. He was not on any active medication. Routine blood investigations showed normal results. Lipid profile was within normal limits. On x ray, lytic lesion measuring $(1.2 \times 1.0 \times 0.8) \mathrm{cm}$ was observed at the right middle finger, proximal phalanx with cortical disruption as seen in Figure 1. An excisional biopsy of the lesion was performed. Fracture reduction was achieved with $\mathrm{K}$-wire and interfragmentary screw. Bone graft was harvested from proximal Ulna and grafting was done at fracture site. A 1.3 $\mathrm{mm}$ locking compression plate (LCP) was introduced and approximated to bone with proximal and distal locking with cortical screws under flouroscopic guidance. Final reduction was confirmed (Figure 2).

The biopsy was sent for histopathological examination. The material submitted consisted grossly of fragments of bone and soft tissue. Histological examination revealed multiple bits of bone trabeculae surrounded by fibro-collagenous stroma. Sheets of large cells with abundant foamy, fine vacuolated cytoplasm and small round nuclei were seen along with occasional mulitinucleate giant cell. Few of the bits showed haemorrhage and granulation tissue (Figure 3). Findings were favouring a diagnosis of bone xanthoma. Immunohistochemistry was performed on formalin fixed, paraffin embedded sections to rule out non-neoplastic and neoplastic fibrohistiocytic lesions and neoplastic lesion like metastatic renal cell carcinoma, considering the histology and age of the patient. The results were as follows: S-100- negative, CD68- positive in foamy cells, Pan Cytokeratin- Negative, Vimentin- Negative, CD10Negative. A final diagnosis of primary xanthoma of bone was made. The patient was advised active range of motion exercise. On follow up the patient is improving with good range of motion.

\section{Discussion}

Primary bone xanthoma is a rare bone disorder which usually presents in patients above 20 years of age and has a male to female ratio of 2:1. ${ }^{[1]}$ Primary xanthomas of bone more often involve the flat bones than the long bones with the mandible, temporal bone, ribs, and pelvic bones being most commonly involved by the condition. ${ }^{[7]}$ There 


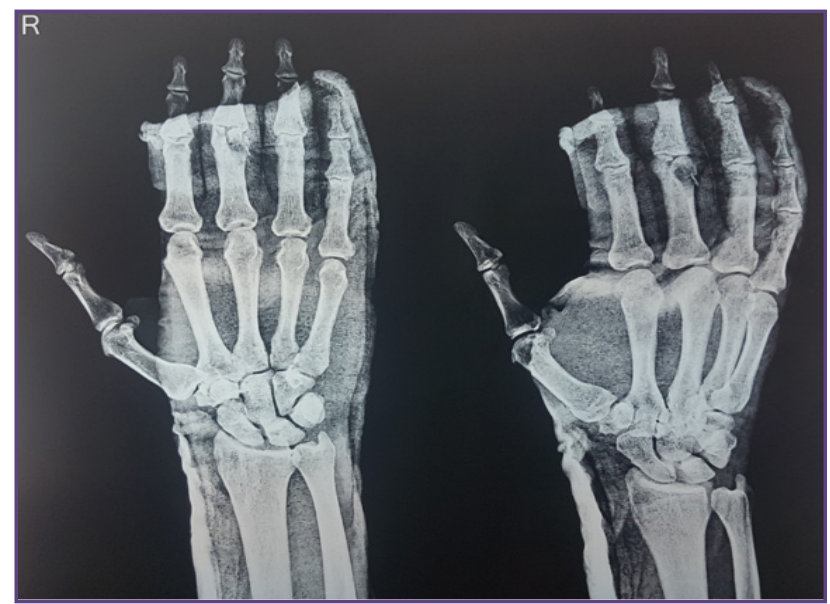

Fig. 1: $\mathrm{X}$ ray image showing a lytic lesion in the middle phalanx of the right middle finger.

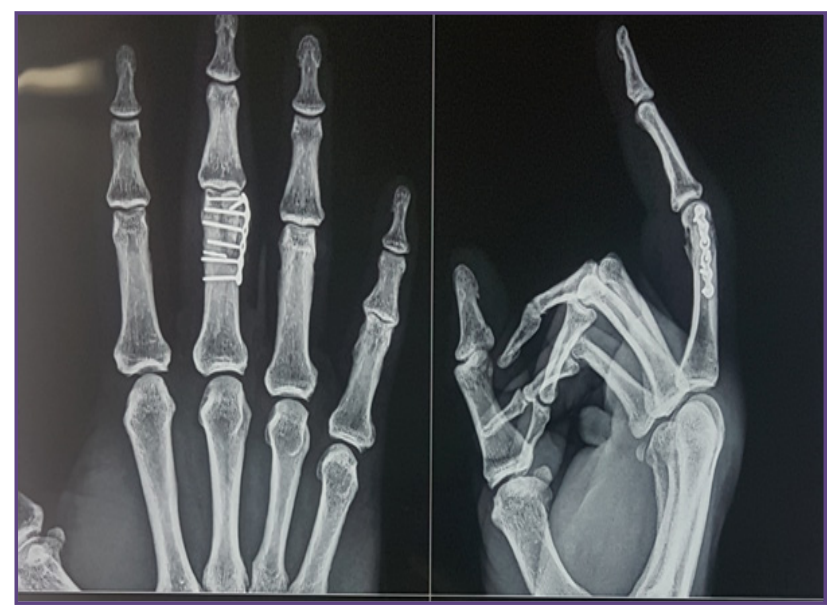

Fig. 2: $\mathrm{X}$ ray showing fracture reduction using $\mathrm{k}$ wire and screws.

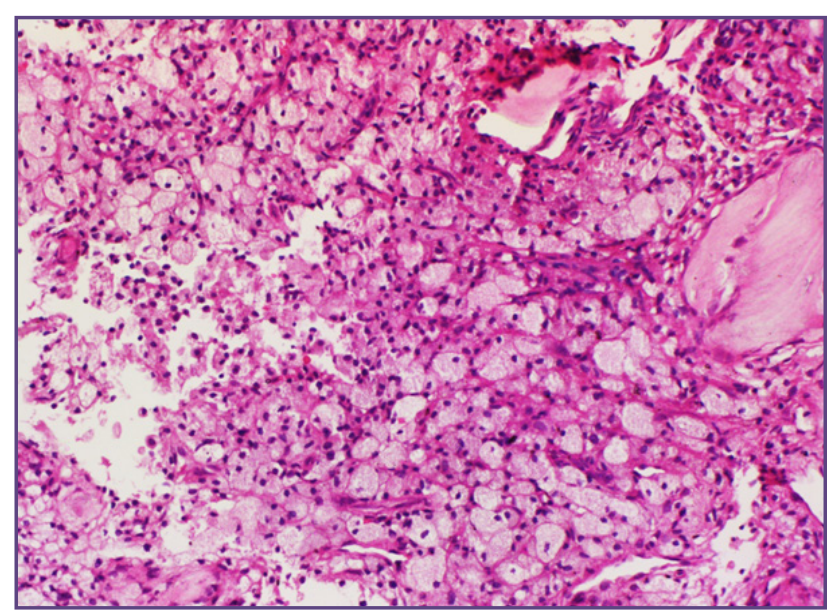

Fig. 3: Sheets of large cells with foamy to finely vacuolated cytoplasm and small round nucleus, H\&E x400. are reported cases of Primary intraosseous xanthomas of the jaws, which affect the posterior mandible (86\%) of normolipemic patients, with a mean age of 30 years and no gender predilection. ${ }^{[8]}$

They may disrupt the cortical bone and very rarely may extend into the surrounding soft tissues. These are usually small lesions ranging in size between $2-5 \mathrm{~cm}$. [5,9] Histologically, it is characterized by mononuclear macrophage-like cells, abundant foam cells, and multinucleated giant cells. It is sometimes discovered coincidentally and the most frequent symptom is pain. ${ }^{[1]}$

It has been reported in association with hyperlipidaemia and hypo-lipoproteinemia and occasionally with diabetes mellitus. ${ }^{[10]}$ So diet control, lifestyle modification, and treatment of associated condition may help in regression of the bone xanthoma with lipid disorders. ${ }^{[11]}$

Rare cases of primary bone xanthoma are reported in nonhyperlipidaemic states. ${ }^{[12,13]}$ Though its etiology remains unclear, ${ }^{[14]}$ a mild trauma may be a causative factor. ${ }^{[14,15]}$ These are characterized by the presence of cholesterol deposits in the bone which occurs as a result of the leakage of lipid from the blood vessels at the site of the lesion which is then taken up by the macrophages. ${ }^{[10,16,17]}$ Some authors consider xanthomatous lesions as neoplastic under the broad categoryof benign fibrous histiocytomas, while others favor a "primary" xanthoma of bone as a separate reactive entity. ${ }^{[18]}$ Bertoni et al proposed the term primary xanthoma of bone for those cases in which no apparent underlying condition can be identified and the predominant finding is a collection of foam cells. Some authors considered these lesions to be non-neoplastic in origin and not variants of $\mathrm{BFH}$, a lesion they consider requiring a spindle cell component with clinical and radiographic evidence of a low-grade neoplasm. ${ }^{[19]}$

Differential diagnosis includes non-neoplastic and neoplastic lesions like Rosai-Dorfman disease, Langerhans cell histiocytosis and fibrous/post traumatic dysplasia, malignant fibrous histiocytoma, or metastatic renal cell carcinoma. [18,19]. In generalized lesions, underlying hyperparathyroidism requires exclusion. In children, another possibility is a nonossifying fibroma or fibrous cortical defect. ${ }^{[18]}$

Radiographically, it is a well-defined lesion, sometimes expansile, lytic, often with a sclerotic margin. MRI is characterized by a circumscribed area of low and high signal intensity on T1 and T2 weighted images respectively and associated low intensity areas on fat suppressed images which is supposed to be due to the cholesterol- 
laden histiocytes seen on histopathology. [1] Radiological differential diagnosis includes other lytic bone lesion like giant cell tumor. As done in this case, radiological evaluation as well as biochemical investigation for hyperlipidemia and diabetes is necessary to differentiate primary from secondary bone xanthoma.

Clinical history along with radiological findings of a lytic lesion should help in differential diagnosis. Histopathologic evaluation is diagnostic. Biopsy obtained from the lesion is grossly solid, granular, and dull yellow and sometimes a solitary cystic lesion. ${ }^{[4,5]}$ Histologically, it presents as sheets of foamy macrophages, occasional multinucleated giant cells, cholesterol clefts and fibrosis. ${ }^{[19]}$ Immunohistochemstry may be used as an axillary tool to confirm presence of CD68- positive sheets of foamy cells and to rule out other benign spindle cell tumors, RosaiDorfman disease, Langerhans cell histiocytosis, malignant fibrous histiocytoma, and conventional renal cell carcinoma which can be a differential diagnosis. In the present case, diagnosis was obtained after histopathologic evaluation in a case that presented with fracture of middle phalanx of right middle finger. Treatment of choice for bone xanthoma after biopsy confirmation is either by treatment of the underlying hyperlipidemia or curettage and bone grafting as in the reported case here. Performing internal fixation of associated fracture, and advising non weight bearing, depends on the location of the lesion. Intra-lesional curettage removes all gross disease and usually is sufficient for local control. ${ }^{[1,5-6]}$

\section{Conclusion}

Bone xanthoma should be considered in the differential diagnosis of an adult patient with a lytic bone lesion. Diagnosis of bone xanthoma requires a clinical, radiological and histopathological correlation and immunohistochemistry to rule out other neoplastic and non-neoplastic lesions as differential diagnosis. Primary bone xanthoma is treated surgically and may require bone grafting whereas secondary bone xanthoma usually regresses after the medical management of the associated metabolic disorder.

\section{Acknowledgements}

Financial and material support: None

There is no conflict of interest whatsoever.

\section{Funding}

None

\section{Competing Interests}

None

\section{References}

1. Ahmed G, Al Dosari M, El-Mahi M, Abolfotouh S. Primary xanthoma of calcaneus bone: Case report. Int J Surg Case 2014; 5: 699-702.

2. Wang Z, Wei Z, Huang L, Ke1Z, Luo C, et al. Primary nonhyperlipidemiaxanthoma of bone: a case report with review of theliterature.Int J ClinExp Med 2014; 7: 45034508 .

3. Guerrouj H, Mouaden A, BenRais N. Xanthoma of Bone: A CaseReport. Case Rep Endocrinol 2012

4. Ali S, Fedenko A, Matcuk G, Patel D, Gottsegen C, et al. Bilateralprimary xanthoma of the humeri with pathologic fractures: A case report. World J Radiol 2013; 5: 345-348.

5. Yaligod V, Mahesh S, Rudrappa GH, Choudhary L. Xanthoma of ulna. Journal of Evolution of Medical and Dental Sciences 2013; 35: 6691-6695.

6. Chakravarthi V, Aruna E, Chandra Raao DN, Ranga Rao D. Bilateral Tibia Xanthoma in a Normolipidemic PatientReport of a RareCase with Review of Literature. Int J Clin Med 2012;3: 234-237.

7. Alhaneedi, Ghalib \& Salameh, Motasem \& Abu Hejleh, Hasan Azzam. (2018). Xanthoma of Bone: A Mini Review-2471-2671-1000130. Surgical Oncology. 04.

8. Wilkinson, P.E., Merkourea, S., Gopalakrishnan, R. et al. Primary Intraosseous Xanthomas of the Jaws: A Series of Six Cases Including an Example with Formation of Apoptosis-Related Hyaline Globules, So-Called "Thanatosomes". Head and Neck Pathol 2020; 14: 859-868.

9. Kumar K, Matos Y, Thirkannad S. Intraosseous xanthoma of thedistal radius a report. Hand Surg 2014;19: 223-226.

10. Wang Z, Lin ZW, Huang LL, Ke ZF, Luo CJ, Xie WL, Wang LT. Primary non-hyperlipidemia xanthoma of bone: a case report with review of the literature. Int J Clin Exp Med 2014; 7(11): 4503-8.

11. DeMoraes RF, de Padua JM, Silva-Sousa YT, de Almeida OP, Da CPD. Primary xanthoma ofthe mandible. DentomaxillofacRadiol 2011;40: 393-396.

12. Boisgard S, Bringer $\mathrm{O}$, Aufauvre $\mathrm{B}$ et al., Xanthomeosseuxsansdésordrelipidique: À propos d'un cas et revue de lalittérature. Revue du Rhumatisme 2000; $1: 83-86$.

13. Ayadi-Kaddour, Mlika M, Marghli A, Kilani T, and Mezni FE, "Xanthoma of the rib without hyperlipoproteinemia," Respiratory Medicine CME 2008; 1: 40-42.

14. Elwood ET, Shahwan TG, Dajani N, Murray JD. Isolated xanthoma of the frontal bone. J Cr-aniofacSurg 2005; 16: 391-394.

15. Asano K, Sato J, Matsuda N, Ohkuma H. A rarecase of primary bone xanthoma of the clivus. Brain Tumor Pathol 2012; 29: 123-128.

16. Yokoyama K, Shinohara N, and Wada K, Osseous xanthomatosis and a pathologic fracture in a patient with hyper- 
lipidemia. A case report. Clinical Orthopaedics and Related Research 1988; 236: 307-310.

17. Dallari D, Marinelli A, Pellacani A et al., Xanthoma of bone: first sign of hyperlipidemia type IIB: a case report. Clinical Orthopaedics and Related Research 2003; 410: 274-277.
18. Bertoni F, Unni KK, McLeod RA, Sim FH: Xanthoma of bone. Am J ClinPathol 1988; 90:377-384.

19. Macdonald D, Fornasier V, Holtby R. Benign fibrohistiocytoma (xanthomatous variant) of the acromion: a case report and review of the literature. Archives of pathology \& laboratory medicine. 2002; 126:599-601.

*Corresponding author:

Dr. Raji Naidum Dept. of Pathology, BARC Hospital, Anushakti Nagar, Mumbai- 400094

Phone: +91 9619920707

Email: drrajipillai@gmail.com

Date of Submission : 12/01/2021

Date of Final Revision : 13/03/2021

Financial or other Competing Interests: None.

Date of Acceptance : 09/04/2021

Date of Publication : 30/04/2021 